\title{
E-Commerce Readiness Assessment in Sarawak
}

\author{
Ahmad Termidzi Bin Serojai, Hamimah Binti Ujir, Irwandi Hipni Bin Mohamad Hipiny
}

Faculty of Computer Science and Information Technology, Universiti Malaysia Sarawak, 94300 Kota Samarahan, Sarawak, Malaysia

Corresponding author: Hamimah Binti Ujir (uhamimah@unimas.my)

\begin{abstract}
This study explores the factors of e-commerce adoption among Sarawakians. One of the factors is the level of cybersecurity awareness. We aim to assess the readiness for e-commerce among Sarawakians due to the lack of study conducted on the subject. A research model based on the perceived risk (PR), perceived usefulness (PU) and perceived quality of products (PQ), and the intention (I) of adoption of e-commerce services in Sarawak is proposed. The validity of the proposed model is then tested using various validity tests such as item reliability, construct validity, convergent validity and discriminant validity via the SmartPLS software. Once the validity of the model has been determined, a structural equation model is used to study the strength of the model before the test of the hypothesis can be done. The effect size, f2, is calculated by using SmartPLS. The index value of each variable is also plotted in the importance-performance matrix analysis (IPMA). Based on the survey data from 128 end users in Sarawak, the study finds that PU is the most crucial factor in adopting e-commerce services, followed by PQ. Surprisingly, PR does not play any role in the intention of Sarawakians to adopt e-commerce services. The results suggest several important key points as follows: (i) the Sarawak Government and its e-commerce partners should focus on educating the people of Sarawak on the importance of cybersecurity to prevent cyber-related crimes from occurring and causing massive damage in Sarawak's attempt to digitise its economy; (ii)Sarawakians prefer functional e-commerce services; (iii) the quality of e-commerce products should also be maintained; and (iv) the developers should focus on the usefulness of their products to ensure that their service can be adopted by the people of Sarawak.
\end{abstract}

\section{Keywords}

Sarawak; E-commerce; E-readiness; Technology acceptance; Structural equation modelling. 


\section{Introduction}

According to the Australian Trade and Investment Commission (2020), from 2018 and 2019, Malaysia had the biggest increase in total e-commerce activities (46.5 percent) in ASEAN and Malaysia is forecast to have the highest growth rate (35 percent) for total e-commerce activities in ASEAN for the period 20182023. More people are becoming more reliant on e-commerce platforms, with 76 percent of Malaysians shopping online at least once a month in 2017, an increase of 9 percent compared to the previous year (SME \& Entrepreneurship Magazine, 2017). Sarawak, one of the thirteen states in Malaysia, is aiming to improve its economic growth, reduce the socio-economic divide and increase youth employment by the introduction of a digital economy in Sarawak (State Service Modernisation Unit, 2017).

The Sarawak Digital Economy Strategy (SDES) is an initiative introduced by Sarawak's Chief Minister Abang Zohari in 2017 (State Service Modernisation Unit, 2017). The SDES aims to digitalize Sarawak by 2030 and the first strategy of this ambitious attempt ranges from 2018 to 2022 (Teo, 2018). The Sarawak Multimedia Authority (SMA) has been established to govern the digital economy implementation in the state, which currently focuses on sectors such as agriculture, tourism, smart cities, manufacturing, digital health, digital government and e-commerce (State Service Modernisation Unit, 2017).

E-commerce is a growing industry in Sarawak. The Sarawak Government has been encouraging the implementation of e-commerce in the state to include e-commerce in the SDES. The usage of internet devices in Sarawak has been increasing steadily from $77.8 \%$ in 2017 to 83.4\% in 2019 (Department of Statistics Malaysia, 2020b). Since e-commerce has been reliant on internet services, some Sarawak areas have yet to have proper internet facilities. Although e-commerce will provide more choices at lower prices than conventional stores, people in rural areas will not benefit from e-commerce. However, there has been little study on the readiness for e-commerce service adoption among Sarawakians to determine the current state of Sarawakians' readiness for adopting e-commerce services.

With the increasing risk of cybersecurity-related incidents (PYMNTS.COM \& Signifyd, 2017), the level of cybersecurity awareness among Sarawakians should be assessed. They need to be aware of the danger of exposing their data to the internet, which can cause damage to them if they are not careful. Besides that, with the Sarawak Government's encouragement of e-commerce, developers need to learn which areas of the service design should be focused on to ensure the adoption of their services.

With increasing reliance on e-commerce, there are some issues concerning implementation of this technology. Challenges such as cybersecurity awareness have yet to be studied. Besides that, the level of readiness for the adoption of e-commerce among Sarawakians should also be studied.

This study focuses on the challenges of e-commerce and the readiness of Sarawakians for the implementation of e-commerce services in the state. The study aims to assess the level of readiness of Sarawakians for the use of e-commerce, depending on their perceived risk, perceived quality and perceived usefulness of the service. The importance of the usefulness and the quality of products provided by the services are also part of the motivation. Another aspect that we also include in the study is the effect of product quality on the adoption of e-commerce services, which, according to Nisar \& Prabhakar (2017), increases customers' loyalty.

This paper presents findings from the survey conducted on Sarawakians on their readiness for the adoption of e-commerce. Section 2 describes the related works in this field. We present data collection, data pre-processing and our framework in Section 3, followed by the experiment setting, results and analysis in Section 4. Finally, the conclusions are drawn. 


\section{Background}

E-commerce has numerous advantages such as time saving, price and product comparison, absence of boundaries, lower transaction costs, more effortless transactions than physical stores, faster buying procedures and low operating costs. It has also provided many opportunities for new technologies to emerge in improving the sector. Malaysia's geographical location can also promote e-commerce technology (Khan et al., 2010).

\subsection{Readiness for e-commerce adoption}

Although Malaysia has its strengths in implementing e-commerce, such as good IT infrastructure and government interest in e-commerce, it also has some weaknesses. Some workers and the older generation are computer-illiterate (Khan et al., 2010). According to Hussin et al. (2018), Malay women entrepreneurs in Kuching, Sarawak, are still yet to adopt e-commerce as their business platform. The obvious limitation is because they are unaware of the benefits that they can gain in adopting e-commerce. Yet, lack of adoption occurs although they are aware of the significant advantages and the positive influence of ecommerce on their businesses.

\subsection{E-commerce adoption in Sarawak}

There is currently no reputable study regarding Sarawak's level of e-commerce readiness, although it is one of the states of Malaysia and has at least 23 different ethnic groups with major groups such as Malay, Iban, Chinese and Bidayuh (Sarawak State Government, 2016).

There is also a study conducted on Malay women entrepreneurs in Kuching, Sarawak which was conducted by Hussin et al. (2018). The study concluded that due to the lack of awareness of the benefits of adopting e-commerce, there is also a lack in adopting e-commerce. The study focuses on entrepreneurs rather than end users.

\subsection{Technology acceptance model}

The technology acceptance model (TAM) is a model that is used in explaining influential factors and mechanisms of technology use and was introduced by Davis (1986). It is an adaption of the theory of reasoned action (TRA), which was developed by Fishbein \& Ajzen in 1975, specializing in user acceptance of information technology systems (Davis et al., 1989). The TAM was developed to explain the factors affecting computer acceptance. The TAM was designed to be general and capable of explaining users' behaviour across a broad range of computing technologies and user populations. The primary function of the TAM is to provide the basis for tracing the impact of external factors on internal beliefs, attitudes and intentions.

The TAM was also used by a study conducted by Tzavlopoulos et al. (2019) to determine the factors of quality of e-commerce products on customers' loyalty, satisfaction, value and perceived risk. The results showed that the quality of the user interface increases the perceived value of e-commerce services, while the ease of use, responsiveness of the service and service personalization can increase the overall satisfaction of end users. Tzavlopoulos et al. (2019) conducted studies on 298 respondents from different backgrounds in Greece. The study also determined that perceived risk plays a significant role in the adoption of e-commerce in Greece.

The TAM is widely used in the study of various sectors, such as education (Scherer et al., 2018), M-learning (Al-Emran et al., 2018), health (Rahimi et al., 2018), as well as new technology adoption such as sports wearables (Kim \& Chiu, 2019). The review has also determined TAM use in new technology implementation readiness such as M-learning, telehealth and internet banking. Although Sarawak is aiming to become a state in Malaysia to implement a digital economy (State Service Modernisation Unit, 
2017), few studies of digital economy in general or e-commerce, particularly in Sarawak, exist. One study that has been conducted in Sarawak is on the adoption of e-commerce by women entrepreneurs by Hussin et al. (2018). The study concluded that there is an obvious limitation in the adoption of e-commerce among the group due to the lack of awareness of benefits of adopting e-commerce despite being aware of the significant advantages and the positive influence of e-commerce on their businesses.

\section{Research Methodology}

The study will focus on the quantitative study of possible factors affecting e-commerce readiness among Sarawakian by using questionnaires and ranking the choice of answers by using a Likert scale from "Strongly Disagree" at score 1 to "Strongly Agree" at score 5. The study uses deductive reasoning by testing previous theory on perceived risk, perceived usefulness and perceived quality of products in the context of Sarawakians.

\subsection{Data collection}

The study managed to collect 128 survey respondents via Google Forms and the survey is distributed out via social media such as Facebook, Twitter and WhatsApp due to travel restrictions hindering collection of proper respondents since the COVID-19 pandemic was looming large in Sarawak during the time of this study. The questions are designed mainly according to the study design of Al-Najjar \& Jawad (2016). The questions are also adjusted according to the test suitability. The questions were asked in both English and Malay to reduce misunderstandings. Table 1 shows the following types and number of questions for the study.

Table 1. Types and number of questions in the questionnaire.

\begin{tabular}{|c|c|}
\hline Types of questions & Number of questions \\
\hline Demographics & 6 \\
\hline E-commerce awareness & 2 \\
\hline Perceived risk & 2 \\
\hline Perceived usefulness & 3 \\
\hline Perceived quality & 4 \\
\hline Intention behaviour & 4 \\
\hline
\end{tabular}

Table 2. Sarawak division according to zones. Source: Malaysia Praying Time Zone.

\begin{tabular}{|l|l|}
\hline Zone & Location \\
\hline Zone 1 & Limbang, Sundar, Terusan, Lawas \\
\hline Zone 2 & Niah, Belaga, Sibuti, Miri, Bekenu, Marudi \\
\hline Zone 3 & Song, Belingan, Sebauh, Bintulu, Tatau, Kapit \\
\hline Zone 4 & Igan, Kanowit, Sibu, Dalat, Oya \\
\hline Zone 5 & Belawai, Matu, Daro, Sarikei, Julau, Bintangor, Rajang \\
\hline Zone 6 & Kabong, Lingga, Sri Aman, Engkelili, Betong, Spaoh, Pusa, Saratok, Roban, Debak \\
\hline Zone 7 & Samarahan, Simunjan, Serian, Sebuyau, Meludam \\
\hline Zone 8 & Kuching, Bau, Lundu, Sematan \\
\hline
\end{tabular}


The demographic questions were asked to filter respondents that are suitable for the study. Demographic questions such as age, gender, location, educational level, monthly income and job status were asked to classify respondents according to their demographic groups. The respondents were given the option to choose their location based on zones as listed in Table 2. Meanwhile, e-commerce awareness questions were used to determine the level of e-commerce awareness among the respondents. The questions used well-known e-commerce websites in Malaysia, such as Shopee and Lazada, to familiarize them with the idea of e-commerce services.

\subsection{Research model}

Perceived risk (PR) is defined as the customer's perception of risk in e-commerce transactions (Al-Najjar \& Jawad, 2016). Security plays a significant role in providing customers with satisfaction and a sense of trust. Therefore, this study focuses on the following hypotheses:

H1: Perceived risk negatively influences the intention to use e-commerce among Sarawakians.

H10: Perceived risk has no impact on the intention to use e-commerce among Sarawakians.

Perceived usefulness (PU) is defined as the presumption of effortlessness of using the e-commerce system while at the same time providing clear benefits compared to the costs needed to implement e-commerce. The following hypothesis has been formulated to study the effects of PU on the intention to use ecommerce.

H2: Perceived usefulness positively influences the intention to use e-commerce among Sarawakians.

H20: Perceived usefulness has no impact on the intention to use e-commerce among Sarawakians.

Perceived quality $(\mathrm{PQ})$ is defined as the quality of the products obtained by purchasing via e-commerce. Thus, the study focuses on the following hypothesis on PQ.

H3: Perceived quality positively influences the intention to use e-commerce among Sarawakians.

H30: Perceived quality has no impact on the intention to use e-commerce among Sarawakians.

Figure 1 below shows the theoretical technology acceptance model (TAM) of e-commerce readiness among Sarawakians.

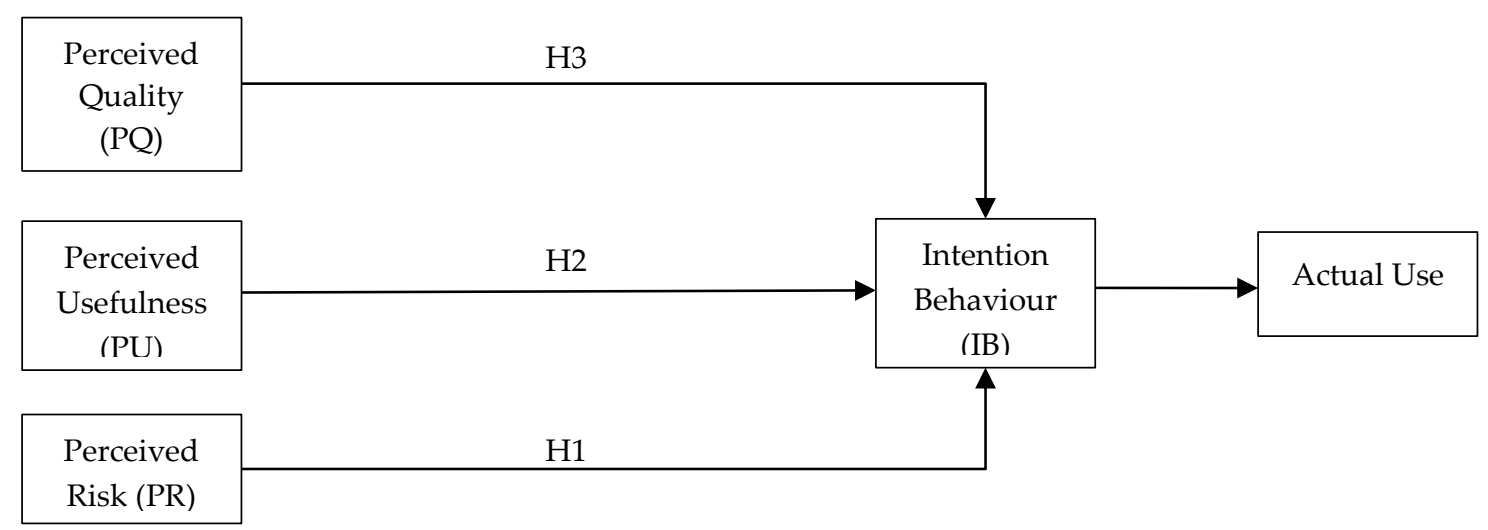

Figure 1. Theoretical technology acceptance model (TAM) of e-commerce readiness among Sarawakians.

\subsection{Data analysis method}

The SmartPLS software is used to determine the TAM construct validity stated in Figure 1 by using partial least square analysis to figure out the latent variable scores (Henseler et al., 2009). Data obtained from the questionnaires are analysed statistically to determine the correlation between the factors as designed in 
Table 3 above. Convergent validity is the measurement taken to determine whether the factors represented in the questions converge into a common construct (Carlson \& Herdman, 2012). Quality criteria for convergent validity, such as Cronbach's alpha $(\alpha)$, composite reliability (CR) and average variance extracted (AVE), are applied.

Table 3. Criteria for model assessment measurement.

\begin{tabular}{|c|c|c|c|}
\hline Validity type & Criteria & Guidelines & References \\
\hline Item reliability & Item loadings & Loadings $>0.5$ & (Nunnally, 1978) \\
\hline \multirow{2}{*}{ Construct validity } & Cronbach's alpha $(\alpha)$ & $\alpha \geq 0.7$ & $\begin{array}{c}\text { (Nunnally \& Bernstein, } \\
\text { 1994) }\end{array}$ \\
\hline & Composite reliability (CR) & $\mathrm{CR}>0.7$ & $\begin{array}{c}\text { (Nunnally \& Bernstein, } \\
1994)\end{array}$ \\
\hline $\begin{array}{l}\text { Convergent } \\
\text { validity }\end{array}$ & $\begin{array}{c}\text { Average variance extracted } \\
\text { (AVE) }\end{array}$ & AVE $>0.5$ & $\begin{array}{c}\text { (Fornell \& Larcker, } \\
\text { 1981) }\end{array}$ \\
\hline \multirow{3}{*}{$\begin{array}{l}\text { Discriminant } \\
\text { validity }\end{array}$} & Cross loadings & $\begin{array}{c}\text { Loadings }>\text { cross-loadings on } \\
\text { other constructs }\end{array}$ & (Chin, 1998) \\
\hline & Fornell-Larcker criterion & $\begin{array}{c}\sqrt{ } \text { AVE }>\text { correlation with other } \\
\text { constructs }\end{array}$ & $\begin{array}{c}\text { (Fornell \& Larcker, } \\
\text { 1981) }\end{array}$ \\
\hline & $\begin{array}{l}\text { Heterotrait-monotrait ratio } \\
\text { (HTMT) }\end{array}$ & Construct correlation $\leq 0.85$ & (Henseler et al., 2015) \\
\hline
\end{tabular}

Discriminant validity differentiates the constructs from each other. The average variance shared by each construct should be greater than the average between the construct to other constructs to pass the discriminant validity test (Compeau et al., 1999). Another method of analysing the discriminant validity of a model is by comparing the cross-loadings for every construct. The loadings for each outer construct should be higher when compared to its latent variable compared to other latent variables. Besides crossloading, the heterotrait-monotrait ratio (HTMT) is another method to determine a model discriminant validity. The HTMT value should not exceed 0.85 to pass the discriminant validity analysis.

After both convergent and discriminant validity are analysed, multicollinearity must be tested to determine the model strength. Multicollinearity among variables is not preferred due to the difficulty of developing methodology guidelines among researchers (Kock \& Lynn, 2012). A lateral collinearity test (VIF) will be conducted to determine the multicollinearity among variables.

Regression analysis is used to determine whether the three hypotheses stated above are accepted or not. SmartPLS, with a bootstrapping calculation method, is used to test the hypotheses. The t-value and pvalue are calculated to determine whether the null hypotheses, where the factors have no effect at all on the consumers' willingness to adopt e-commerce services, are accepted by using regression analysis. The $\mathrm{t}$-value must be away from 0 , while the p-value must be below the threshold of 0.05 and 0.01 to reject the null hypothesis, hence concluding that the factors do provide some effects on the adoption of e-commerce services.

After the test for the null hypothesis, each construct's effect size must be determined to study which latent variable has more effect on the model than others (Cohen, 2013). The effect size is used to determine which of the latent variables can be improved even further in a future study. Developers can also use the effect size to determine which factors need more emphasis to design their e-commerce service system. 
Importance-performance matrix analysis (IPMA) is then conducted to determine which construct has the most importance-performance ratio and determining which construct needs more improvement for a better model. The IPMA will be presented in a graph figure, which will help the reader determine the effects of each latent variable.

\section{Results and Discussion}

The analyses conducted are explained in the following subsections: descriptive analysis, convergent and discriminant validity analyses, model regression, structural equation model and IPMA.

\subsection{Descriptive analysis}

The data in Table 4 have a slight skewness towards female respondents at 76 (59.38\%) compared to male respondents at $52(40.63 \%)$. The age range has a healthy mix with most respondents between the age of 26 and 30, at $60(46.88 \%)$ respondents. The respondents also came from various educational backgrounds, with undergraduate degree holders making up the greatest part of the respondents at $60(46.88 \%)$. The mod income range is between RM2,001 and RM3,000 at $31(24.22 \%)$ respondents, followed by an income range of RM3,001 and RM4,000 at 29 (22.66\%) respondents. Twenty respondents declared their income as none. Out of the 20, fourteen were full-time students and six were unemployed at the time of the survey.

Location-wise, the respondents are mostly from Zone 8 (Kuching, Lundu, Bau and Sematan) with 60 $(46.88 \%)$ respondents. One possible explanation for this heavy skewness is that people living in Zone 8 have an easier access to social media compared to respondents living in the other zones. Based on the criteria set by the Department of Statistics Malaysia (2020a), 63.28\% (81 people) of the respondents are classed as the B40 group, with a household income of below RM3,720. The remaining respondents belongs to the M40 group, and none belongs to the T20 group, since the threshold for T20 is RM8,650.

Table 4. Demographic profile of the respondents.

\begin{tabular}{|c|c|c|}
\hline Demographic characteristics & Frequency & Percentage $(\%) n=128$ \\
\hline \multicolumn{3}{|l|}{ Gender } \\
\hline Female & 76 & 59.38 \\
\hline Male & 52 & 40.63 \\
\hline \multicolumn{3}{|l|}{ Age } \\
\hline Less than 20 & 9 & 7.03 \\
\hline 21-25 years old & 25 & 19.53 \\
\hline 26-30 years old & 60 & 46.88 \\
\hline 31-35 years old & 11 & 8.59 \\
\hline $36-40$ years old & 12 & 9.38 \\
\hline $41-45$ years old & 7 & 5.47 \\
\hline $46-50$ years old & 1 & 0.78 \\
\hline 51 years old and above & 3 & 2.34 \\
\hline \multicolumn{3}{|l|}{ Hometown } \\
\hline Zone 1 & 2 & 1.56 \\
\hline Zone 2 & 18 & 14.06 \\
\hline
\end{tabular}




\begin{tabular}{|l|c|c|}
\hline Demographic characteristics & Frequency & Percentage (\%) n=128 \\
\hline Zone 3 & 9 & 7.03 \\
\hline Zone 4 & 14 & 10.94 \\
\hline Zone 5 & 9 & 7.03 \\
\hline Zone 6 & 11 & 8.59 \\
\hline Zone 7 & 5 & 3.91 \\
\hline Zone 8 & 60 & 46.88 \\
\hline
\end{tabular}

Malaysians are currently using numerous e-commerce websites, a combination of direct sales and marketplaces (Lelong) or pure marketplace models (PrestoMall, Shopee, Lazada). The Australian Trade and Investment Commission (2020) tabled the comparison of Malaysia's largest e-commerce platforms. In this study, the respondents were asked regarding their awareness of the existence of these websites. It is concluded that all respondents have heard at least of one of the e-commerce websites listed in the questionnaire. Shopee ranked first in the list, with 127 (99.22\%) of the respondents having heard of the ecommerce service. Lazada followed Shopee as the second most heard-of e-commerce website, followed closely by Zalora with 125 (97.66\%) and 117 (91.41\%) respondents, respectively. Only 1 (0.78\%) respondent has never heard of any of the e-commerce websites listed in the survey.

\subsection{Measurement model assessment}

Based on Table 5, the model passes the convergent validity test, with each factor loading exceeding the minimum requirement of 0.5 . With Cronbach's alpha for each latent factor exceeding 0.7 , this proves that the model is reliable. The model also passes the convergent validity test with both CR and AVE exceeding the recommended value of 0.7 and 0.5 , respectively. After convergent validity has been tested, the model was tested for its discriminant validity to make sure that the latent factors are genuinely different from each other (Fornell \& Larcker, 1981). According to Fornell \& Larcker (1981), the square root of AVE for each latent factor must be higher than the correlation of the latent variables. Table 8 below shows the results of discriminant validity based on Fornell \& Larcker's (1981) recommendation.

Table 5. Measurement model results.

\begin{tabular}{|l|c|l|l|l|}
\hline Constructs & Loading & $\boldsymbol{\alpha}$ & CR & AVE \\
\hline Perceived Risk & PR & 0.739 & 0.828 & 0.714 \\
\hline PR1 & 0.995 & & & \\
\hline PR2 & 0.662 & & & \\
\hline Perceived Usefulness & PU & 0.733 & 0.844 & 0.644 \\
\hline PU1 & 0.818 & & & \\
\hline PU2 & 0.731 & & & \\
\hline PU3 & 0.853 & & & \\
\hline Perceived Quality & PQ & 0.856 & 0.901 & 0.694 \\
\hline PQ1 & 0.830 & & & \\
\hline PQ2 & 0.833 & & & \\
\hline PQ3 & 0.856 & & & \\
\hline
\end{tabular}




\begin{tabular}{|l|c|l|l|l|}
\hline Constructs & Loading & $\boldsymbol{\alpha}$ & CR & AVE \\
\hline PQ4 & 0.813 & & & \\
\hline Intention Behaviour & IB & 0.888 & 0.923 & 0.749 \\
\hline I1 & 0.911 & & & \\
\hline I2 & 0.902 & & & \\
\hline I3 & 0.792 & & & \\
\hline I4 & 0.852 & & & \\
\hline
\end{tabular}

Table 6. Measurement model discriminant validity.

\begin{tabular}{|l|l|l|l|l|}
\hline & $\begin{array}{l}\text { Intention } \\
\text { Behaviour }\end{array}$ & $\begin{array}{l}\text { Perceived } \\
\text { Quality }\end{array}$ & $\begin{array}{l}\text { Perceived } \\
\text { Risk }\end{array}$ & $\begin{array}{l}\text { Perceived } \\
\text { Usefulness }\end{array}$ \\
\hline Intention Behaviour & 0.866 & N/A & N/A & N/A \\
\hline Perceived Quality & 0.432 & 0.833 & N/A & N/A \\
\hline Perceived Risk & -0.237 & -0.382 & 0.845 & N/A \\
\hline Perceived Usefulness & 0.599 & 0.484 & -0.342 & 0.802 \\
\hline
\end{tabular}

Table 7. Loadings and cross-loadings.

\begin{tabular}{|l|c|c|c|c|}
\hline Constructs & $\begin{array}{l}\text { Intention } \\
\text { Behaviour }\end{array}$ & $\begin{array}{l}\text { Perceived } \\
\text { Quality }\end{array}$ & $\begin{array}{l}\text { Perceived } \\
\text { Risk }\end{array}$ & $\begin{array}{l}\text { Perceived } \\
\text { Usefulness }\end{array}$ \\
\hline I1 & 0.911 & 0.44 & -0.311 & 0.624 \\
\hline I2 & 0.902 & 0.397 & -0.236 & 0.487 \\
\hline I3 & 0.792 & 0.279 & -0.071 & 0.444 \\
\hline I4 & 0.852 & 0.356 & -0.164 & 0.494 \\
\hline PQ1 & 0.347 & 0.83 & -0.377 & 0.371 \\
\hline PQ2 & 0.445 & 0.833 & -0.188 & 0.444 \\
\hline PQ3 & 0.332 & 0.856 & -0.319 & 0.417 \\
\hline PQ4 & 0.271 & 0.813 & -0.459 & 0.362 \\
\hline PR1 & -0.252 & -0.387 & 0.995 & -0.344 \\
\hline PR2 & -0.033 & -0.204 & 0.662 & -0.194 \\
\hline PU1 & 0.371 & 0.373 & -0.242 & 0.818 \\
\hline PU2 & 0.39 & 0.38 & -0.2 & 0.731 \\
\hline
\end{tabular}


Table 8. Heterotrait-monotrait (HTMT) of the model structure.

\begin{tabular}{|l|c|c|c|c|}
\hline & IB & PQ & PR & PU \\
\hline Intention Behaviour (IB) & & & & \\
\hline Perceived Quality (PQ) & 0.471 & & & \\
\hline Perceived Risk (PR) & 0.197 & 0.445 & & \\
\hline Perceived Usefulness (PU) & 0.695 & 0.598 & 0.389 & \\
\hline
\end{tabular}

In Table 6, the italicised values are the square root of the AVE. According to Fornell \& Larcker's recommendation, the model passes the discriminant validity test as all the square roots of AVE are higher than the correlation of the latent variables. Based on the validity test results in Table 7 and Table 8, both convergent and discriminant validity tests have been successfully passed.

Factor loadings and cross-loadings can also determine the discriminant validity test (Chin, 1998). The outer loading, or the questions, should have higher values when analysed with its latent variable, compared to other latent variables. The model discriminant validity will fail if there are values higher than the outer loading in its latent variable. Table 7 shows the results for cross-loading.

As shown in Table 7, all outer loading values are higher compared to their latent variables. The outer loadings have a much lower value than other latent variables, indicating that the model discriminant validity is developed. Table 8 shows the model HTMT results, and all loadings score well below the limit of 0.85 , with PU to IB ratio the highest at 0.695 .

\subsection{Structural equation model}

After the model convergent and discriminant validity has been established, the model strength must be determined. It can be achieved by using a structural equation model (SEM) (Ringle et al., 2015). Various tests must be done, such as the lateral collinearity test (VIF). R2 values and t-values, following the suggestions of Hair et al. (2014), are needed to test for the VIF. The bootstrapping calculation method with 5000 samples is required according to Hair et al. (2009), who suggest to conduct SEM testing by using SmartPLS software.

Multicollinearity among variables is not preferred due to the difficulty in deriving clear researchers' methodology guidelines (Kock \& Lynn, 2012). There is a considerable acceptable value for VIF. Hair et al. (2010) stated that the minimum acceptable threshold for VIF is 10. Therefore, according to Kock \& Lynn (2012), the ideal VIF value must be below 3.3 for each construct to indicate no lateral collinearity among the latent variables. Table 9 shows the lateral collinearity between the latent variables, which are well below 3.3.

Table 9. Latent collinearity assessment results.

\begin{tabular}{|l|c|c|c|c|}
\hline & IB & PQ & PR & PU \\
\hline Intention Behaviour (IB) & N/A & N/A & N/A & N/A \\
\hline Perceived Quality (PQ) & 1.404 & N/A & N/A & N/A \\
\hline Perceived Risk (PR) & 1.217 & N/A & N/A & N/A \\
\hline Perceived Usefulness (PU) & 1.357 & N/A & N/A & N/A \\
\hline
\end{tabular}




\subsection{Test for hypotheses}

The bootstrapping method with 5000 resamples is suggested by Hair et al. (2009) to test for hypothesis acceptance. The test is done with 0.01 significance levels. Beta $(\beta)$ is the path coefficient calculated using SmartPLS software using the PLS algorithm.

Table 10. Hypothesis testing $(p<0.01)$.

\begin{tabular}{|l|c|c|c|c|c|l|}
\hline Hypothesis & Relationship & $\boldsymbol{\beta}$ & $\begin{array}{c}\text { Standard } \\
\text { Deviation }\end{array}$ & T-value & p-value & Decision \\
\hline H1 & PR->IB & 0.009 & 0.087 & 0.107 & 0.457 & $\begin{array}{l}\text { Not } \\
\text { supported }\end{array}$ \\
\hline H2 & PU->IB & 0.512 & 0.073 & 7.017 & 0.000 & Supported \\
\hline H3 & PQ->IB & 0.187 & 0.080 & 2.351 & 0.009 & Supported \\
\hline
\end{tabular}

Based on Table 10 above, the hypothesis on perceived risk affecting the intention to use e-commerce negatively is not accepted. The reason is that the $t$-value for the hypothesis is closer to zero, indicating that the sample accepts the null hypothesis. Besides that, the p-value for $\mathrm{H} 1$ exceeds the threshold of 0.01 at 0.457 . The result means that there is a possibility of $45.7 \%$ of the sample accepting the null hypothesis. Therefore, with a high p-value, the null hypothesis that the perceived risk has no effect on the readiness for e-commerce adoption cannot be wholly rejected, and hence H1 is rejected.

For the other two hypotheses (H2 \& H3), the null hypotheses are rejected since the t-values are further away from 0 . Besides that, the p-values for both hypotheses are accepted within the significance levels of 0.01 with H2: 0.000 and $\mathrm{H} 3: 0.009$, respectively. $\mathrm{H} 2$ and $\mathrm{H} 3$ can be accepted with a chance of $1 \%$ of null hypotheses occurring due to the random sample effect.

\subsection{Effect size}

To understand which of the variables have a larger effect than the others, p-values cannot be used since they can only show that the effect exists (Cohen, 2013) but not the effect size. Therefore, $\boldsymbol{R}^{\boldsymbol{2}}$ can be used to view the combined effect of the variables. Cohen (2013) suggested that the cut-off $\boldsymbol{R}^{2}$ is 0.02 for weak, 0.13 for moderate, and 0.26 for substantial. The intention path has an $\boldsymbol{R}^{2}$ value of 0.385 , which exceeds the substantial cut-off recommended by Cohen (2013). Cohen (2013) also suggested using the $f^{2}$ value to study the effect size of each hypothesis. The $f^{2}$ is obtained by using the formula below:

$$
f^{2}=\frac{R^{2}}{1-R^{2}}
$$

The model is then tested with $\boldsymbol{Q}^{\mathbf{2}}$ values, used to determine whether the model has any predictive relevance (Cohen, 2013). The $\boldsymbol{Q}^{\mathbf{2}}$ values can be calculated by using SmartPLS with the blindfolding calculation method. The model needs to have a $\boldsymbol{Q}^{2}$ value of more than 0.00 to indicate any predictive relevance (Cohen, 2013). The formula for finding the $\boldsymbol{Q}^{2}$ value is shown below. The SSE is the sum of squares of prediction errors, while the SSO is the sum of squares of observations (Henseler et al., 2009). The SSE and SSO values for each latent variable are shown in Table 11 below.

$$
Q^{2}=\frac{1-S S E}{S S O}
$$


Table 11. Values of SSE, SSO and $Q^{2}$.

\begin{tabular}{|c|c|c|c|}
\hline Constructs & SSO & SSE & $\begin{array}{c}\mathbf{Q}^{2}=\mathbf{1 -} \\
\text { SSE/SSO }\end{array}$ \\
\hline IB & 512.000 & 371.956 & 0.274 \\
\hline PQ & 512.000 & 512.000 & N/A \\
\hline PR & 256.000 & 256.000 & N/A \\
\hline PU & 384.000 & 384.000 & N/A \\
\hline
\end{tabular}

Table 12. Effect size evaluation.

\begin{tabular}{|c|c|c|c|c|c|}
\hline Path & Constructs & $\mathbf{R}^{2}$ & $\mathbf{Q}^{2}$ & $\mathbf{f}^{2}$ & Decision \\
\hline & $\begin{array}{c}\text { Intention } \\
\text { Behaviour }\end{array}$ & 0.385 & 0.274 & N/A & Substantial \\
\hline H1 & PR->IB & N/A & N/A & 0.00 & No effect \\
\hline H2 & PU->IB & N/A & N/A & 0.314 & Medium \\
\hline H3 & PQ->IB & N/A & N/A & 0.041 & Small \\
\hline
\end{tabular}

The results in Table 12 shows that $\mathrm{H} 1$ has no effect, $\mathrm{H} 2$ has the largest effect with a medium effect size, while H3 has a little effect size. Since the partial least square structural equation model (PLS-SEM) does provide a critical analysis on the model, the IPMA provides the extension of the results obtained from the PLS-SEM (Hair et al., 2018). Table 13 shows the index values for each latent variable and the total effect scores of the IPMA model variable. Based on the results, it can be concluded that PU is the most crucial factor for determining the intention of e-commerce adoption among Sarawakians. PQ is the intermediate factor, and PR has the lowest level of importance in determining the intention of e-commerce adoption.

Table 13. Index values and total effects of latent variables.

\begin{tabular}{|l|c|c|}
\hline $\begin{array}{l}\text { Latent } \\
\text { variables }\end{array}$ & $\begin{array}{c}\text { Total effect of latent variables on intention to use e-commerce } \\
\text { services }\end{array}$ & $\begin{array}{c}\text { Index values } \\
\text { (performance) }\end{array}$ \\
\hline PQ & 0.187 & 53.677 \\
\hline PR & 0.009 & 43.362 \\
\hline PU & 0.512 & 65.522 \\
\hline
\end{tabular}

Based on Table 13, e-commerce services depend significantly on their usefulness to ensure that Sarawakians will adopt them. Therefore, any local Sarawak companies trying to provide e-commerce services within the state should provide services that the people deem useful to allow them to adopt the service.

\subsection{Discussion}

Based on our findings, we can conclude that Sarawakians' adoption of an e-commerce service depends chiefly on the service's usefulness (PU). The second most important factor is the quality (PQ) of the products sold by the e-commerce service. Interestingly, we observed that Sarawakians deem perceived risk (PR) as a non-factor during their decision-making process. 
The third finding contradicts Tzavlopoulos et al. (2019), according to whom perceived risk is considered an important factor for would-be e-commerce service users in Greece. Based on our survey data, we can conclude that Sarawakians consider perceived risk as a non-issue since there is not enough evidence against the null hypothesis. None of the respondents answered "disagree" or "strongly disagree" for questions on using e-commerce services. One potential explanation for this behaviour is the lack of cybersecurity awareness among Sarawakians. We argue that most Sarawakians are unaware of the potential severity of harm caused by identity theft and data leakage, hence the lackadaisical attitude to the involved risks when adopting a new e-commerce service. This needs to be addressed promptly by increasing the number (and reach) of campaigns for educating the public about cybersecurity. This call is in line with the State Government's plan to increase the awareness and knowledge of cybersecurity among individuals and organizations in Sarawak, as well as improving the resilience of Sarawak's digital environment against cybersecurity threats (State Service Modernisation Unit, 2017).

Nevertheless, this study is limited in term of the balance of the respondents location-wise. Sixty (46.88\%) of the respondents came from Zone 8, consisting of people from Kuching, Bau, Lundu and Sematan. More respondents from big cities such as Sibu, Miri and Bintulu are needed since a large population of smartphone users reside there. A more balanced distribution of the respondents location-wise is preferable to better capture the demography for the whole of Sarawak.

\section{Conclusion}

This study was conducted to gauge the readiness for adoption of e-commerce services among Sarawakians. The study focuses on measuring the importance of perceived usefulness, perceived quality of products and perceived risk in Sarawakians' decision whether to adopt a new e-commerce service. Both perceived usefulness and perceived quality of products play an important role in the decision process. Worryingly, the perceived risk is a non-factor among Sarawakians. Since e-commerce services are mushrooming with no sign of slowing down, the State Government should amplify its effort of promoting cybersecurity awareness and safety via educational campaigns and policy-making.

For our future work, we plan to increase the number of respondents from other zones. A more equally distributed data set will better capture the demography of the whole of Sarawak. Also, more factors can be addressed in the future survey, such as perceived privacy, perceived quality of services, perceived ease of use and perceived costs of use.

\section{Additional Information and Declarations}

Acknowledgements: The authors fully acknowledge Universiti Malaysia Sarawak for all the support that makes this important research viable and effective.

Conflict of Interests: The authors declare no conflict of interest.

Author Contributions: A.T.S.: data curation, conceptualization, writing - original draft preparation. H.U.: supervision, validation, writing - reviewing and editing. I.H.: writing reviewing and editing.

Data Availability: The data that support the findings of this study are available from the corresponding author.

\section{References}

Al-Emran, M., Mezhuyev, V., \& Kamaludin, A. (2018). Technology Acceptance Model in M-learning context: A systematic review. Computers and Education, 125, 389-412. https://doi.org/10.1016/j.compedu.2018.06.008

Australian Trade and Investment Commission. (2020). E-Commerce in Malaysia: A Guide for Australian Business, Commonwealth of Australia 2020. 
Carlson, K. D., \& Herdman, A. O. (2012). Understanding the impact of convergent validity on research results. Organizational Research Methods, 15(1), 17-32. https://doi.org/10.1177/1094428110392383

Chin, W. W. (1998). Issues and Opinion on Structural Equation Modeling. MIS Quarterly, 22(1), vii-xvi.

Compeau, D., Higgins, C. A., \& Huff, S. (1999). Social cognitive theory and individual reactions to computing technology: A longitudinal study. MIS Quarterly, 23(2), 145-158. https://doi.org/10.2307/249749

Department of Statistics Malaysia. (2019). Press Release for Statistics on Usage of Ict and E-Commerce By Establishment 2018. In Newsletter of the Department of Statistics Malaysia (Issue May). Department of Statistics Malaysia.

Department of Statistics Malaysia. (2020a). Laporan Survei Pendapatan Isi Rumah Dan Kemudahan Asas Mengikut Negeri Dan Daerah Pentadbiran - Sarawak. Department of Statistics Malaysia.

Department of Statistics Malaysia. (2020b). Poket Stats Negeri Sarawak ST1 2020. https://www.dosm.gov.my/v1/uploads/files/7 Publication/Infographic/PocketStats/Negeri/Sarawak/ST12020/Poket Stats Sarawak ST1 2020.pdf

Fornell, C., \& Larcker, D. F. (1981). SEM with Unobservable Variables and Measurement Error: Algebra and Statistics. Journal of Marketing Research, 18(3), 1-16.

Hair Jr., J. F., Hult, G. T. M., Ringle, C. M., \& Sarstedt, M. (2016). A Primer on Partial Least Squares Structural Equation Modeling (PLS-SEM). SAGE Publications.

Hair Jr., J. F., Sarstedt, M., Ringle, C. M., \& Gudergan, S. P. (2018). Advanced Issues in Partial Least Squares Structural Equation Modeling. SAGE Publications.

Henseler, J., Ringle, C. M., \& Sarstedt, M. (2015). A new criterion for assessing discriminant validity in variance-based structural equation modelling. Journal of the Academy of Marketing Science, 43(1), 115-135. https://doi.org/10.1007/s11747-014-0403-8

Henseler, J., Ringle, C. M., \& Sinkovics, R. R. (2009). The use of partial least squares path modeling in international marketing. Advances in International Marketing, 20, 277-319. https://doi.org/10.1108/S1474-7979(2009)0000020014

Hussin, H. H., Jemari, M. A., Kasuma, J., Yacob, Y., \& Panie, R. (2018). Factors Influencing E-Commerce Adoption Among Malay Women Entrepreneurs in Kuching Sarawak. Journal of Borneo-Kalimantan, 3(1), 1-19. https://doi.org/10.33736/jbk.614.2017

Khan, M. J., Dominic, P. D. D., \& Khan, A. (2010). Opportunities and challenges for E-commerce in Malaysia: A theoretical approach. In Proceedings of the 2010 2nd International Conference on Electronic Computer Technology, (pp. 189-192). IEEE. https://doi.org/10.1109/ICECTECH.2010.5479962

Kim, T., \& Chiu, W. (2019). Consumer acceptance of sports wearable technology: the role of technology readiness. International Journal of Sports Marketing and Sponsorship, 20(1), 109-126. https://doi.org/10.1108/lJSMS-06-2017-0050

Kock, N., \& Lynn, G. S. (2012). Lateral Collinearity and Misleading Results in Variance-Based SEM: An Illustration and Recommendations. Journal of the Association for Information Systems, 13(7), 546-580. https://doi.org/10.1002/ctpp.19740140604

Nisar, T. M., \& Prabhakar, G. (2017). What factors determine e-satisfaction and consumer spending in e-commerce retailing? Journal of Retailing and Consumer Services, 39, 135-144. https://doi.org/10.1016/j.jretconser.2017.07.010

Nunnally, J. C. (1978). Psychometric Theory. McGraw-Hill.

Nunnally, J. C., \& Bernstein, I. H. (1994). Psychometric Theory. (3rd ed.). McGraw-Hill.

PYMNTS.COM, \& Signifyd. (2017). Global Fraud Index (Issue October). https://cloud.kapostcontent.net/pub/0e602198-76474ff5-a4e8-9e16eeb1769a/global-fraud-index-q2-2017.pdf?kui=MuD47nlvGWDFbGY0Wg7IMw

Rahimi, B., Nadri, H., Afshar, H. L., \& Timpka, T. (2018). A systematic review of the technology acceptance model in health informatics. Applied Clinical Informatics, 9(3), 604-634. https://doi.org/10.1055/s-0038-1668091

Ringle, C. M., Wende, S., \& Becker, J. M. (2015). SmartPLS 3. SmartPLS GmbH.

Sarawak State Government. (2016). Sarawak Facts and Figures. https://www.data.gov.my/data/ms MY/dataset/sarawakfacts-and-figures

Scherer, R., Siddiq, F., \& Tondeur, J. (2018). The Technology Acceptance Model (TAM): A Meta-Analytic Structural Equation Modeling Approach to Explaining Teachers' Adoption of Digital Technology in Education. Computers \& Education, 128, 13-35. https://doi.org/10.1016/j.compedu.2018.09.009

SME \& Entrepreneurship Magazine. (2017). 76 percent of Malaysians Shop Online At Least Once a Month. https://sme.asia/76-percent-of-malaysians-shop-online-at-least-once-a-month/

State Service Modernisation Unit. (2017). Sarawak Digital Economy Strategy 2018-2022: An Overview Booklet. http://www.sarawak.gov.my/ebook/DEbooklet/

Teo, R. (2018). Sarawak's drive towards electronic payments. The Borneo Post. https://www.theborneopost.com/2018/12/23/sarawaks-drive-towards-electronic-payments/

Tzavlopoulos, I., Gotzamani, K., Andronikidis, A., \& Vassiliadis, C. (2019). Determining the impact of e-commerce quality on customers' perceived risk, satisfaction, value and loyalty. International Journal of Quality and Service Sciences, 11(4), 576-587. https://doi.org/10.1108/lJQSS-03-2019-0047 
Editorial record: The article has been peer-reviewed. First submission received on 15 April 2021. Revisions received on 31 May 2021, and 29 June 2021. Accepted for publication on 5 July 2021. The editors coordinating the peer-review of this manuscript were Chiew Kang Leng (D) and Zdenek Smutny (D. The editor in charge of approving this manuscript for publication was Zdenek Smutny.

Special Issue: Inspiring Technologies for Digital Inclusivity. Selected papers from the $12^{\text {th }}$ International Conference on Information Technology in Asia (CITA'21).

Acta Informatica Pragensia is published by Prague University of Economics and Business, Czech Republic.

ISSN: $1805-4951$ 